\title{
Changes in PPARS Protein Content following Acute Aerobic Exercise in Human Vastus Lateralis Muscle
}

Nicholas P. Greene, Mats I. Nilsson, Bradley S. Lambert, Steven E. Riechman, James D. Fluckey, Stephen F. Crouse

Texas A\&M University

Int J Exerc Sci 2(1): S23, 2009. PPARS is a transcription factor which functions in the regulation of lipid and glucose metabolism, and may be implicated as a therapeutic target for several metabolic diseases. Exercise training has previously been shown to increase PPAR $\delta$ protein content, but the response of PPAR $\delta$ to acute exercise is not yet understood. PURPOSE: To explore changes in PPARS protein content following an acute bout of aerobic exercise in untrained obese adults. METHODS: 8 men and 4 women participated in the study. Subjects' mean age, weight, $\mathrm{VO}_{2 \mathrm{MAX}}$ (Bruce treadmill GXT), and body composition (DEXA) were $44 \mathrm{yr}, 93.2 \mathrm{~kg}, 28.2 \mathrm{~mL} / \mathrm{kg} / \mathrm{min}$, and 40.5\% body fat, respectively. Subjects were asked to refrain from exercise for 1 week prior to the experiment and to maintain normal dietary habits during the study. Muscle biopsies were obtained from the vastus lateralis 3 days prior to acute exercise and again 24 hours after exercise. Subjects were exercised on a motorized treadmill at 70\% $\mathrm{VO}_{2 \mathrm{MAX}}$ for a target duration of 400kcal energy expenditure during the exercise session. PPARS protein content in biopsied tissue was determined by Western blot analysis. Data were analyzed by repeated measures ANOVA and expressed as means \pm standard error. RESULTS: PPAR $\delta$ content was enhanced 24 hours following acute exercise in previously untrained, obese adults (unexercised $1.54 \pm 0.38$ vs. exercised $2.30 \pm 0.39$ arbitrary units, $\mathrm{P}<0.05)$. Gel mobility shift indicated no difference in activity of PPAR $\delta$ (phosphorylated: total) following exercise (unexercised $0.36 \pm 0.03$ vs. exercised $0.34 \pm 0.04)$. CONCLUSION: Our study shows that PPARS expression is enhanced in untrained, obese adults following a single bout of aerobic exercise with no relative change in phosphorylation of PPARס. These data indicate that acute exercise plays a role in the expression of PPARS. Funding for this research was provided by HydroWorx International, Inc., the Sydney \& J.L. Huffines Institute for Sports Medicine and Human Performance at Texas A\&M University and The Texas Chapter of The American College of Sports Medicine

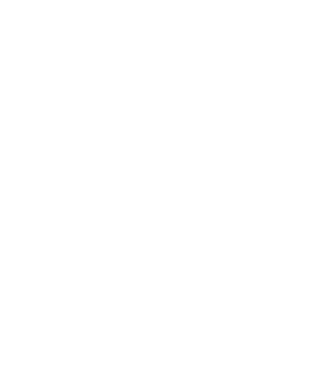

S23 